\title{
Promyelocytic Blast Phase of Chronic Myeloid Leukemia, BCR-ABL1-Positive: Points to be Considered at Diagnosis
}

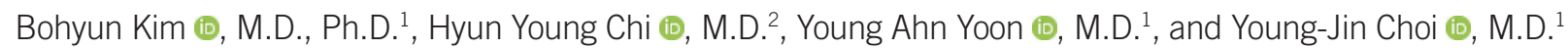 \\ ${ }^{1}$ Department of Laboratory Medicine, Soonchunhyang University Cheonan Hospital, Soonchunhyang University College of Medicine, Cheonan, Korea; \\ 2Samkwang Medical Lab, Seoul, Korea
}

\section{Dear Editor,}

Progression to promyelocytic blast phase (BP) in chronic myeloid leukemia (CML), BCR-ABL1-positive is very rare, and only few cases have been reported since the introduction of Tyrosine Kinase Inhibitor (TKI) therapy [1-3]. However, there are no studies on the important considerations for an accurate diagnosis. We report the case of a patient with promyelocytic BP of $\mathrm{CML}$ after short-term TKI therapy and provide a review on the diagnosis. The Institutional Review Board of Soonchunhyang University Cheonan Hospital, Chungcheongnam-do, Korea, approved this study (file No. 2020-10-036) and exempted the need for informed consent as there was no identifying information and no harm caused to the patient.

A 35 -year-old male patient with leukocytosis $\left(60.55 \times 10^{9} / \mathrm{L}\right)$ was admitted to Soonchunhyang University Cheonan Hospital in March 2017. Bone marrow (BM) study revealed hypercellularity with myeloid and megakaryocytic hyperplasia.Chromosomal analysis revealed 46,XY,t(9;22)(q34;q11.2)[20]. The quantity of major BCR-ABL1 fusion transcript was $30.02 \%$ (Table 1). The patient was diagnosed as having CML, chronic phase (CP). However, he refused TKI therapy.

Two years later (in April 2019), his peripheral blood (PB) smear revealed marked leukocytosis $\left(164.42 \times 10^{9} / \mathrm{L}\right)$, anemia, and thrombocytosis, with $2 \%$ blasts and left-shifted neutrophilic maturation. Newly developed hepatosplenomegaly was detected. BM finding was similar to the previous results, but diffuse myelofibrosis was additionally detected. The result of chromosomal analysis was same as before, but the quantity of $B C R-A B L 1$ fusion transcript increased to $96.17 \%$. The patient was started on dasatinib treatment (100 mg once daily). His leukocyte count normalized during the first month of therapy but gradually increased thereafter.

After two months of dasatinib therapy, the patient complained of oral bleeding. PB smear showed leukocytosis with $97 \%$ abnormal promyelocytes, anemia, and thrombocytopenia. The disseminated intravascular coagulation (DIC) score calculated using the International Society on Thrombosis and Haemostasis scoring system was 9 (Table 1) [4]. BM study revealed $96.20 \%$ abnormal promyelocytes (Fig. 1A). Immunophenotype of abnormal promyelocytes was consistent with acute promyelocytic leukemia (APL). Chromosomal analysis revealed 46,XY,t(9;22)(q34; q11.2),t(15;17)(q24;q21)[20]. The quantity of BCR-ABL1 fusion transcript was $53.22 \%$. Multiplex reverse transcriptase-PCR and interphase fluorescence in-situ hybridization (FISH) detected both major BCR-ABL1 and PML-RARA fusion transcripts (Fig. 1B-1D). The patient was diagnosed as having promyelo-
Received: June 22, 2020

Revision received: July 13, 2020

Accepted: November 11, 2020

Corresponding author: Bohyun Kim, M.D., Ph.D.

Department of Laboratory Medicine, Soonchunhyang University Cheonan Hospital, 31 Soonchunhyang 6-gil, Dongnam-gu, Cheonan 31151, Korea Tel: +82-41-570-3571, Fax: +82-41-572-2316

E-mail: bhkim@schmc.ac.kr

\section{(c) (1) 9}

\section{(C) Korean Society for Laboratory Medicine}

This is an Open Access article distributed under the terms of the Creative Commons Attribution Non-Commercial License (https://creativecommons.org/licenses/by-nc/4.0) which permits unrestricted non-commercial use, distribution, and reproduction in any medium, provided the original work is properly cited. 
Kim B, et al.

Promyelocytic blast phase of CML

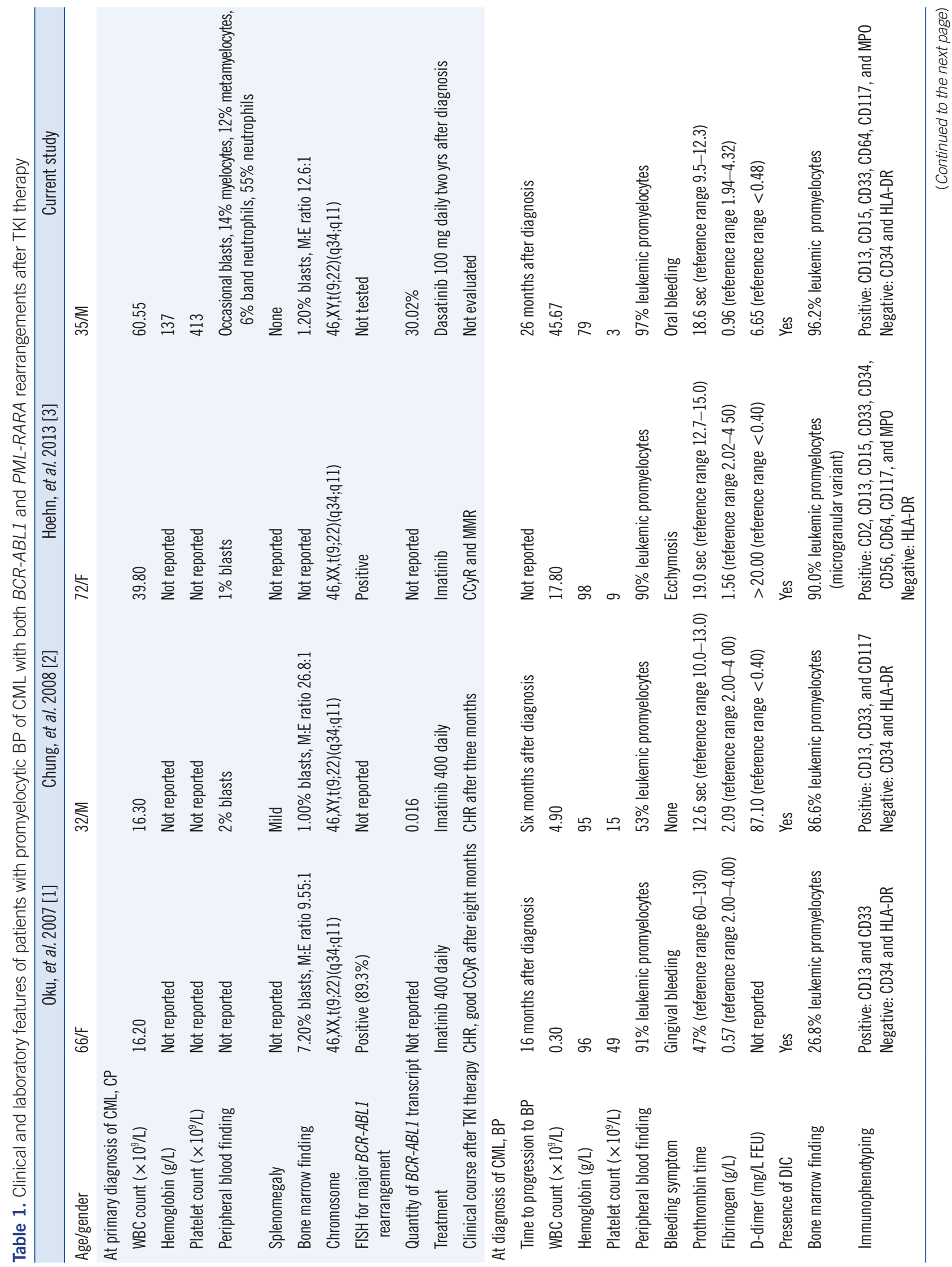




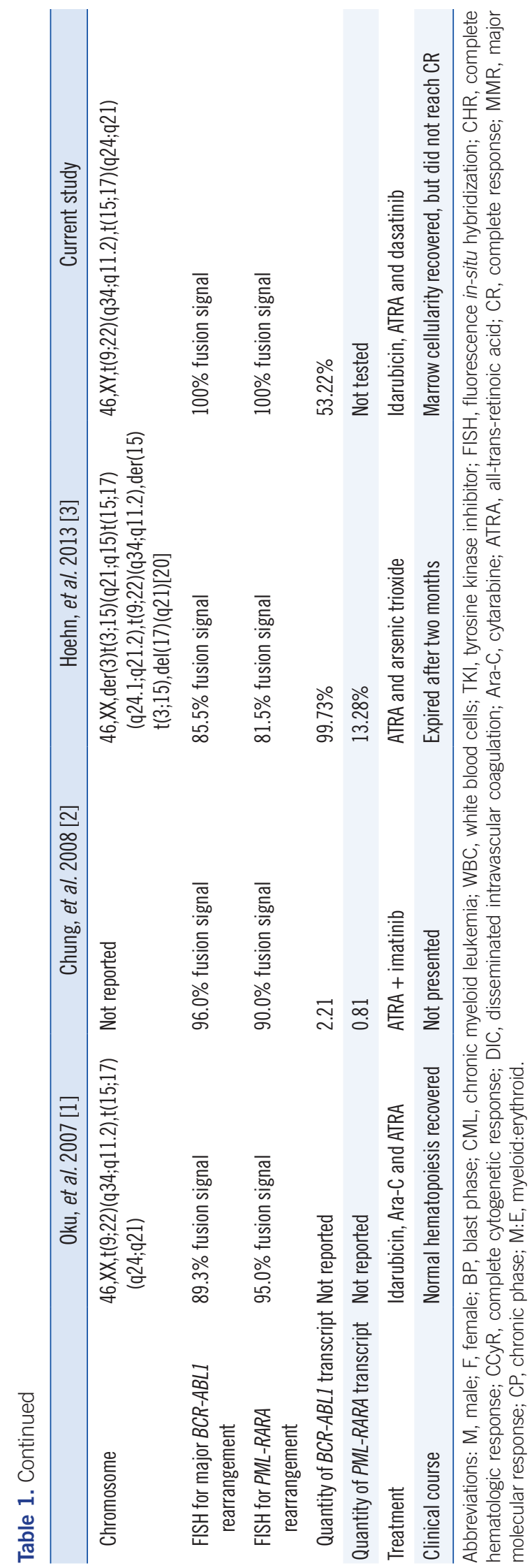

cytic BP of CML and received induction and maintenance chemotherapy. However, complete remission of promyelocytic BP was not achieved, and stem cell transplantation was considered.

We found three reported cases of promyelocytic BP of $\mathrm{CML}$ with $B C R-A B L 1$ and $P M L-R A R A$ rearrangements that have been reported after the introduction of TKI therapy (Table 1) [1-3]. All reported patients were primarily diagnosed as having $\mathrm{CML}, \mathrm{CP}$ and immediately started on TKI therapy for which they showed good response. The time to progression into promyelocytic BP after starting treatment varied from six to 16 months. In contrast, our patient's condition aggravated to promyelocytic BP just two months after starting treatment; therefore, the time was insufficient to evaluate the response to TKI therapy. Most patients showed increased hypergranular abnormal promyelocytes, and immunophenotypes were typical for APL. The quantities of fusion transcripts of $B C R-A B L 1$ and $P M L-R A R A$ were variable, but the proportion of fusion signals in FISH were high in all cases.

The following mechanisms have been suggested for disease progression from CML, CP to common BP despite TKI therapy: competitive advantage to Philadelphia-negative cells with genetic instability, chromosomal aberrations, and mutations of tumor suppressor genes and oncogenes [5, 6]. Specific risk factors for disease progression to promyelocytic $\mathrm{BP}$ of $\mathrm{CML}$ have not been identified so far. Few studies have suggested selective suppression of the Philadelphia-positive clone by TKI and TKIinduced chromosomal aberrations [1, 3]. The longer the delay in starting TKI therapy, the more the cells exposed to genomic instability [5]. This finding suggests that PML-RARA clones may have already existed with the BCR-ABL1 clone before the initiation of TKI therapy and may have multiplied rapidly during TKI therapy, which only killed the BCR-ABL1 clone, although we could not confirm the presence of a PML-RARA clone in the sample used for primary diagnosis.

Among the reported four patients, three showed bleeding symptoms and accompanying DIC. Coagulopathy is frequently observed in APL and is associated with early death [7]. Thus, when CML patients show bleeding symptoms, early detection of disease progression and starting adequate treatment immediately are critical.

Few studies have reported APL with both PML-RARA and $B C R-A B L 1$ rearrangements [8, 9]. If a patient is primarily diagnosed as having APL with both PML-RARA and BCR-ABL1 rearrangements, the possibility of progression of undiagnosed $\mathrm{CML}$ to promyelocytic $\mathrm{BP}$, rather than de novo $\mathrm{APL}$ with both $P M L-R A R A$ and BCR-ABL1 rearrangements should be considered [10]. 

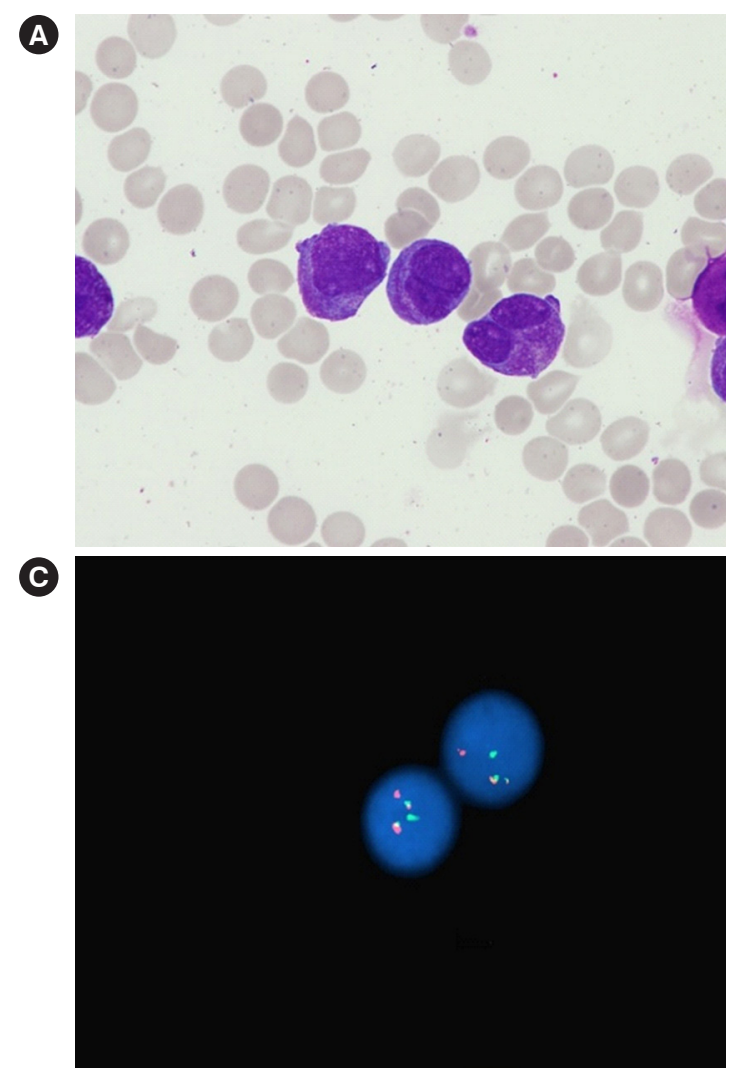

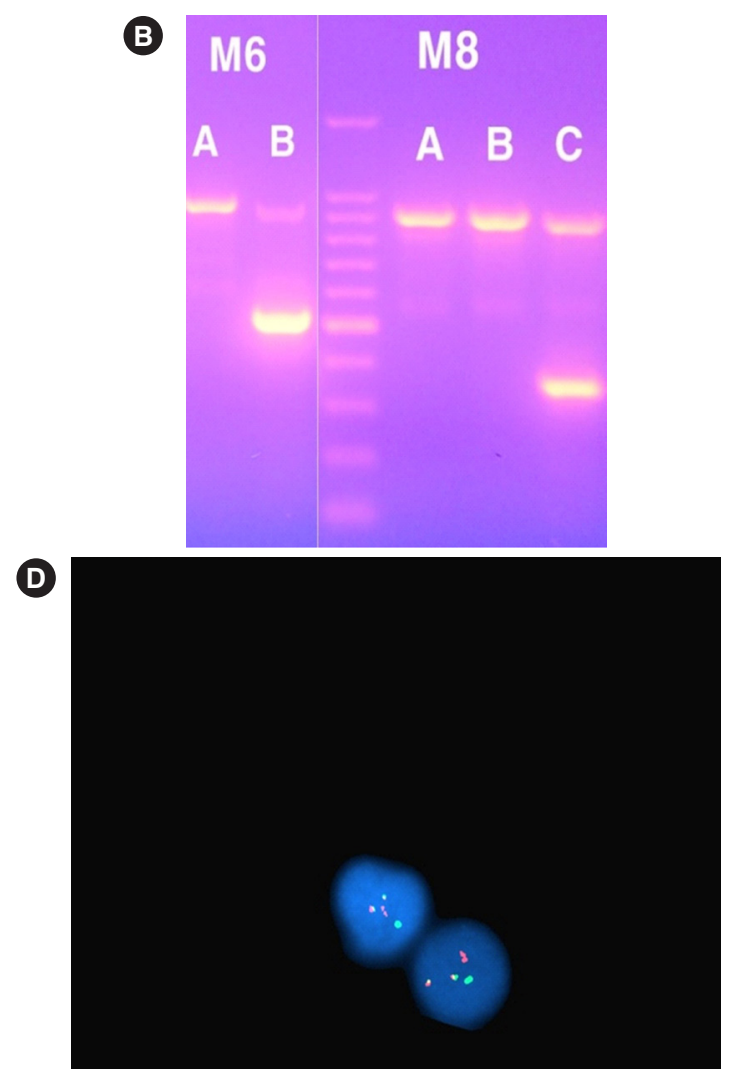

Fig. 1. Results of BM study, RT-qPCR, and FISH assay at the diagnosis of blast phase of CML. (A) Abnormal promyelocytes on a BM aspirate smear (Wright-Giemsa stain, $\times 1,000$ ). (B) RT-qPCR analysis of BCR-ABL1 translocation (HemaVision-28N, DNA Diagnostic, Risskov, Denmark), showing a 397-bp band in the M6B split-out PCR and a 353-bp band in the M8C split-out PCR, indicating BCR-ABL1 (b3a2) and PML-RARA (bcr1 isoform) fusion transcripts. (C and D) FISH using a break-apart probe for BCR-ABL1 and PML-RARA fusion genes (Cytocell, Cytocell Ltd, Oxford Gene Technology, Cambridge, UK) showed two fusion signals, one green and one red, suggesting both BCR$A B L 1$ and $P M L-R A R A$ rearrangements.

Abbreviations: BM, bone marrow; CML, chronic myeloid leukemia; FISH, fluorescence in-situ hybridization; RT-qPCR, quantitative reverse-transcription PCR.

In conclusion, disease progression of $\mathrm{CML}$ to promyelocytic BP should be considered when (1) BCR-ABL1 and PML-RARA rearrangements are detected simultaneously and (2) sudden changes in leukocyte counts or bleeding symptoms occur despite TKI therapy, which could be an important clue suggesting disease progression to promyelocytic BP rather than adverse effects of TKI.

\section{ACKNOWLEDGEMENTS}

None.

\section{AUTHOR CONTRIBUTIONS}

Kim B designed the study and wrote the manuscript. Chi HY analyzed and interpreted the molecular tests. Yoon YA and Choi

YJ interpreted the results of laboratory tests and participated in discussion. All authors read and approved the final manuscript.

\section{CONFLICTS OF INTEREST}

None declared.

\section{RESEARCH FUNDING}

This study was supported by the Soonchunhyang University Research Fund.

\section{ORCID}

Bohyun Kim

Young Ahn Yoon https://orcid.org/0000-0003-4456-5612

https://orcid.org/0000-0002-8284-6303 
Young-Jin Choi

https://orcid.org/0000-0002-7076-5725

Hyun Young Chi

https://orcid.org/0000-0002-5865-9292

\section{REFERENCES}

1. Chung HJ, Chi HS, Cho YU, Park CJ, Seo EJ, Kim KH, et al. Promyelocytic blast crisis of chronic myeloid leukemia during imatinib treatment. Ann Clin Lab Sci 2008;38:283-6.

2. Oku E, Imamura R, Nagata S, Takata Y, Seki R, Otsubo K, et al. Promyelocytic crisis of chronic myelogenous leukaemia during imatinib mesylate treatment. Acta Haematol 2007;117:191-6.

3. Hoehn D, Lu G, Konoplev S, Zhou Y, Bueso-Ramos CE, Zuo Z, et al. $\mathrm{t}(15 ; 17)(\mathrm{q} 24.1 ; \mathrm{q} 21.2) / P M L-R A R A$ in blast phase of chronic myelogenous leukemia: a rare form of clonal evolution. J Hematopathol 2012; 6:187-93.

4. Taylor FB, Jr., Toh CH, Hoots WK, Wada H, Levi M. Towards definition, clinical and laboratory criteria, and a scoring system for disseminated intravascular coagulation. Thromb Haemost 2001;86:1327-30.

5. Radich JP. The biology of CML blast crisis. Hematology Am Soc Hematol Educ Program 2007:384-91.

6. Saußele S and Silver RT. Management of chronic myeloid leukemia in blast crisis. Ann Hematol 2015;94(S2):S159-65.

7. Breen KA, Grimwade D, Hunt BJ. The pathogenesis and management of the coagulopathy of acute promyelocytic leukaemia. $\mathrm{Br} J$ Haematol 2012;156:24-36.

8. An GD, Lim HH, Woo KS, Kim KH, Kim JM, Kim SH, et al. A case of acute promyelocytic leukemia with co-existence of $B C R-A B L 1$ and $P M L$ RARA rearrangements detected by PCR. Lab Med Online 2017;7:196200.

9. Sun X, He Y, Mao C, Zhu L, Qin X, Huang S. BCR/ABL fusion gene detected in acute promyelocytic leukemia: a case study of clinical and laboratory results. Leuk Lymphoma 2014;55:435-8.

10. Chung H, Hur M, Yoon S, Hwang K, Lim H, Kim H et al. Performance evaluation of the QXDx BCR-ABL \%IS droplet digital PCR assay. Ann Lab Med 2020;40:72-5. 